\title{
Personality Development in the Course of Professional Activity
}

\author{
Irina M. Puchkova ${ }^{1}$ \\ ${ }^{1}$ Kazan (Volga region) Federal University, Kazan, Russia \\ Correspondence: Irina M. Puchkova, Kazan (Volga region) Federal University, Kremlyovskaya Street 18, Kazan, \\ 420008, Russia.
}

Received: December 29, 2014

Accepted: January 22, 2015 Online Published: February 11, 2015

doi:10.5539/res.v7n4p133

URL: http://dx.doi.org/10.5539/res.v7n4p133

\begin{abstract}
The actuality of the work is presupposed by the fact that psychological research of interconnection between a person and a profession is of great demand now. It has become an important field of study due to several reasons. First of all it is necessary to have a clear vision of psychological rules of the subject of the activity when he is developing. It is important to specify the role of individual and psychological peculiarities of the person involved in this process. The field of study also concerns the problem of adaptation of the person to the professional activity. The article is aimed at the generalizing of results conducted during long term research of the personality in the process of professional activity with the target of revealing development prospects. The main method used was psychognosis of psychodiagnostics of individual psychological peculiarities of the personality. On the basis of professiographic research and results of psychodiagnostics we conclude in the article that psychological peculiarities of the personality are different either in the level of intensity or structure at the different levels of professional activity. If we look at the professional development from two angles - as the development and as the destruction at the same time then diagnostics and evaluation of the individual psychological peculiarities of the personality at different stages of professional activity could be corrected to avoid destruction. The article could be useful for practitioners psychologists, those who work in the HR sphere.
\end{abstract}

Keywords: personality, professional activity, development, individual psychological peculiarities, important professional qualities

\section{Introduction}

Labour plays a very important role in the life of each person. It is not only a means to support your life but it is a means of perception and transforming of the surrounding world as well, a condition for personality development. The role of the labour as one of the most important types of activity is in its function to be the way for the selfrealization, development and creation of financial wealth and spiritual good.

Last decades marked the importance of study in the sphere of different aspects concerning professional activity. Understanding interrelation between a person and a profession first of all will let us understand psychological mechanisms which influence the development of the person, development the person as the professional, it will either clarify roles of individual psychological peculiarities in this process, ways and methods of process regulation. Secondly this understanding will help us to clear up the question of correspondence of the content, methods and conditions of the working process and psychological peculiarities and abilities of a person. It should also be mentioned that special aspects of the interrelation between a person and object of the professional activity also predefine the problems of mutual adaptation. These directions of study and maintaining of professional activity are presupposed by the criteria of correspondence of the subject's characteristics and characteristics of the activity as well as their adaptability to the solving of professional tasks.

Diagnostics of psychological peculiarities of the professionals, study of the abilities they have for their development and transformation in the process of professional activity, at different stages of the activity will allow to choose the best methods to influence the professional activity which will in turn help to achieve higher levels of the professional success.

Professional development can be described both like mastering and destructions which in the most general sense are the violations of the well known ways of activity. With the growth of professionalism the success of performance will be defined by the scope of factors describing activity features of the person which are being exploited for a long time. Some of them may transform into the features which are not very suitable for the 
professional activity and they can even raise difficulties in professional activity. Using diagnostics and individual psychological peculiarities assessment can help to avoid transformation at different stages and to define these peculiarities.

The aim of the research was to study peculiarities of the personality development of the employees at different stages of professional activity.

Theoretical basis for the research was provided by the theory of professional activity (Karpov, 1988; Pryazhnikov, 2001; Sukhodolsky, 1988; Shadrikov, 1994); job analysis approach applied to the study of working and professional practice (Klimov, 1998; Ivanova, 1992, Bodrov, 2001 and the others); psychological theory of personality (Eysenck, 1952; Maslow, 1954; Sobchick, 2003, etc.)

\section{Materials and Methods}

The experiment was held with the participation of representatives of socionomy professions. Three groups were formed: 1. Those who is just entering the position. 2. Employees with the 1 year working record. 3. Employees with the 2 years working record. The sample group is homogeneous from the point of view of the age-25-30 years, education - higher humanitarian, working record in this particular working environment (the first group lack it, the second has one year, the third-2 years). All the employees have gone through professional selection including the diagnostic of professional important qualities.

Different methods are used for the psychological study of the profession in labour psychology: organizational (comparative, longitude, complex), empirical (study of documentation, observations, study of activity outputs, labour, biographic, experimental); methods of experimental data processing (qualitative and quantative); interpretational methods. Conducting this experiment we used the following methods: study of documentation, surveying, method of personality psychodiognostic. For the purpose of revealing of the individual psychological peculiarities we used: Raymond Cattell's multifactor personality questionnaire (187), Sobchick's typological questionnaire, methodology "Ability to self control”, Timothy Leary's methodology.

\section{Results}

At the initial stage of the experimental study, on the basis of the description of a sale assistant's professional activity professional important qualities were identified. After performing a peer review, the analysis of the results by the method proposed by M. Kendell and B. Smith was conducted. According to this method, the coefficient of concordance, which characterizes the degree of consistency of expert opinion, is calculated.

Received a high degree of consistency of expert opinion.

On the basis of peer review there was received the final list of professional important qualities. These are activism, sociability, discipline, and professional erudition, originality of thinking, intelligence, trainability, resourcefulness, kindness, tact, emotional stability, emotional sensitivity, self-control, diplomacy, friendliness, efficiency, and responsibility.

At the first stage of the analysis of experimental data there was made a statistical comparison of means for the Student's t-test. Picture 1 shows the medium profiles, constructed on the results of a diagnosis by the method of R. Cattell. 


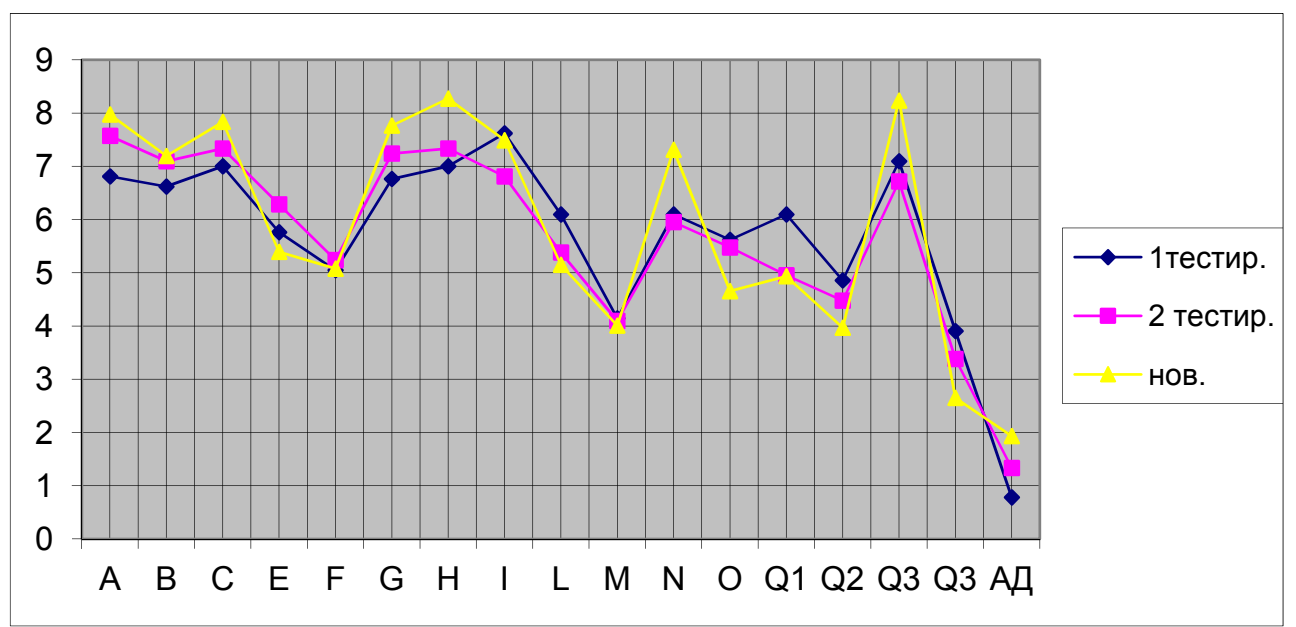

Figure 1. The medium profiles of a diagnosis by the Cattell's test

The following factors can be referred to as the significant ones: factor A (communicativeness), factor B (intelligence, trainability), $\mathrm{C}$ (emotional stability), $\mathrm{G}$ (normative behavior), $\mathrm{H}$ (social courage), I (emotional stability), N (diplomacy), Q3 (self-control), adaptability (composite index, calculated by the formula (A + C + $\mathrm{H})-(\mathrm{L}+\mathrm{O}+\mathrm{Q} 4) / 6$.

Statistical comparison has showed the importance of the following differences.

When comparing the sample of "newcomers" (group 1) and the sample with 1-year experience (group 2) significant differences in the following characteristics were revealed: sociability $(\mathrm{r} \leq 0.05)$, the "newcomers" sociability is above; emotional stability ( $r \leq 0.05)$ is higher in the first group; social courage ( $r \leq 0.01)$, reflecting activity, readiness to deal with new people and circumstances is higher in the first group; diplomacy $(\mathrm{r} \leq 0.05)$ is higher in the first group; self-control $(\mathrm{r} \leq 0.05)$ is higher in the first group; emotional tension $(\mathrm{r} \leq 0.05)$ is higher in the second group; adaptability $(r \leq 0.001)$ is higher in the first group. Also there was observed a trend for a difference by factors $\mathrm{G}$ (index is higher in the first group), Q1 (conservatism-radicalism, indexes are higher in the second group).

When comparing the sample of "newcomers" (group 1) and sample with 2-year working experience (group 2) the significant differences in the level of self-control $(r \leq 0.05)$ were revealed: the first group's index is higher. Also, there was observed a tendency toward differences by factors $\mathrm{H}$ (higher in the first group) and $\mathrm{N}$ (higher in the first group).

When comparing the samples with 1-year experience (the first group) and 2-years (the second group) the significant differences were revealed in the factor "conservatism - radicalism" ( $r \leq 0.05)$, -representatives of the second group are more conservative. Also, there was observed a tendency for a difference by a factor of adaptability (index in the second group is higher).

Summarizing the results of statistical comparison of the diagnostic results, obtained by Cattell's questionnaire, we can conclude that when considering the professional important qualities at different stages of professional activity the following trend is detected: higher indexes are observed in the group of "newcomers", the ones who have no work experience in the professional field. By the end of the first year of work there is the indexes' decrease and, finally, the indexes of sales consultants with experience of 2 years increase slightly, which may indicate a possible trend towards stabilization of professional important qualities.

As a result of statistical comparison of the results of diagnosis by the method of individually typological questionnaire a significant difference in the severity of extraversion in the "newcomers" and sales consultants with 2-years experience (in the first group the index is higher) was revealed. Also the trends for a difference in the groups with 1-year experience and the "newcomers" to the level of anxiety were observed. Since this questionnaire intended to diagnose typological properties that are quite stable and, as already noted, representatives of all groups passed a professional selection, we can conclude the absence of significant differences in the typological properties as the basis of professional important qualities is regularly. 
As a result of the statistical analysis of diagnostic results by the method of "The ability to self-government" there were no significant differences found. There is no "lie scale" in this method and raising the profile for "newcomers" may reflect not the actual level of development of self-components, as desired, but the one they are trying to demonstrate

As a result of the statistical analysis of the data by the method of diagnosis Leary no significant differences were found.

Some reduction of dominance in the group with 1-year experience and increase of the severity of that property in the group with 2 years of experience can show the stabilization of that property on some possibly optimum level.

Correlation analysis, made by the method of K.Pirson, showed that the structure of a personality psychological characteristic differs in all groups. It is less integrated in the first group. The structure of the second group shows the presence of two groups of psychological characteristics: the group that can be called "a group of positive development" because it presents the psychological personality traits that determine the success of the activity. The second group of characteristics can be called "destructive": backbone element in it is an aggression as the reaction to a conflict, which may arise during the work. The structure of the third group is the most integrated with a variety of connections, reflecting the possibility of influence on the person in order to increase the effectiveness of professional activity. Thus, by using the correlation analysis there were revealed the significant differences in the structure of the psychological characteristics of the individual with the release as base especially those that define a successful career at some point.

\section{Discussions}

"With the division of labor the constant and limited scopes of work were isolated and still continue to isolate. Later they called professions: profession is a long-existing set of job duties. Set of occupations of that society provides its needs, performs the necessary functions for society,"-says K. Gurevich (Gurevich, 1970). E. Klimov indicates the diversity of interpretations of the term "profession". By profession can be understood the area in which a person carries out its functions as the subject of labor, or community of people engaged in some kind of job functions, or preparedness (knowledge, skills, qualifications), by which he is able to perform certain kind of work functions, and professional work, that is the process of implementation of labor, professional functionalities. Each of these options corresponds to a certain reality, so they are not only legitimate, but also interrelated (Klimov, 1998).

Man doesn't become a professional immediately, he passes along the way many large and small stages. Moreover, in the professional life of every individual the possibility of repeats and returns ("kickbacks") to the previous levels, as well as zigzags and crises, is very high. Trajectories of path to professionalism can differ very much from each other depending on different people.

Development at different stages and transition from one level of professionalism as well as the movement inside the stage is usually a gradual movement. Further we mention relative levels and stages on the way to become a professional (Nikiforov, Dmitrieva, \& Snetkov, 2003). These levels and stages can be observed to be present simultaneously or co-currently, relatively high levels may coexist with the low ones, which can be considered as a characteristic of individual uniqueness of a professional way of each person.

Industrial psychology pays much attention not only to different stages of professional activity, peculiarities of professional consciousness formation, crisis determination but it also pays much attention to the factors which can influence on the individual peculiarities of the activity subject, change professional important qualities.

Professional distortions are gradually accumulated changes in the patterns of activity and personality that have an adverse effect on productivity and interaction between partners as well as on the development of personality.

Markova distinguishes main tendencies in development of the professional distortions:

- Decelerating in career development in comparison with age, social norms.

- Unformed professional activity (worker "is stuck" in his development).

- Disintegration of professional development and professional consciousness and, as a result—unrealistic goals, false purports of labor, professional conflicts.

- Low labor mobility, inability to adapt to a new work environment.

- Mismatch of professional development elements. The situation when one of these elements anticipates another (e.g., there is motivation for work, but the lack of consistent professional consciousness).

- Reduction of the professional qualities, capabilities; the weakening of professional thinking. 
- Distortion of professional development, emergence of negative qualities that haven't shown up previously; deviation from the social and individual norms of professional development that change personality`s profile.

- Emergence of personality`s deformations (e.g., emotional exhaustion, burnout; defective professional position, especially for jobs with distinct power and fame).

- Discontinuance of professional development owing to occupational disease or disability (Markova, 1996).

Thus professional distortions lead to frustration of personality, reduce adaptability, have an adverse effect on productivity.

Three main groups of factors, determining the professional distortions, are distinguished as follows: 1) objective, related to socio-professional environment (socio-economic situation, profession image, spatial environment); 2) subjective, resulting from type of personality and professional relationships; 3) objective and subjective, deriving from professional process, management quality and professionalism.

More specific psychological determinants of professional distortions are: unconscious and conscious decision`s motives (either reality irrelevant or negative); distortions of expectations are often the triggers at the stage of entering a professional life (first failures prompt to use "extreme" work approaches); formation of stereotypes of professional behavior; on the one part, stereotypes add some stability to work, help to generate unique style of work, on the other part, they prevent from acting adequately in non-typical situations; different types of psychological defense help to reduce degree of uncertainty, to reduce stress. These are: rationalization, negation, projection, identification, alienation; stress, frequent negative emotional states ("burnout"); at the stage of professionalism (especially for those who work with people), as the individual style of work is formed, the level of professional activity drops and conditions for stagnation of professional development emerge; lowering intelligence, as the seniority increase, is caused by work, regulated strictly by norms, when intellectual endowments are not required (unreclaimed endowments go out rapidly); personal «limits» of worker depend on initial educational level, depend on psychological richness of work; the reason for limits emerging can lie in job dissatisfaction; accentuated personality (professional accentuations-some traits of character and profession dependent qualities become excessively strong).

Psychological study and analysis of labor activity with a purpose of solving problems of diagnostics, prediction and forming of professional (vocational) aptitude applies receiving, systematization and use scientific facts, concrete characteristics of labor process, means, conditions and activity arrangement. This complex method of study and description content and structure profession's characteristics with an aim to establish peculiarities of interrelation between subject of labor and activity's components with its functional assurance is called profession's description (profession-graphic). The scientific basis of profession's description is system approach. Profession's description in industrial and organizational psychology is examined as a system description method of subject-object relations in professional activity and as a result of psychological study of professions.

As mentioned above, all aggregate of personality qualities and also the whole series of physical, anthropometric, physiological human's characteristics which determine teaching's successfulness and real activity, was called "professionally important qualities" (PIQ) of subject of activity. The peculiar list of these qualities is specific for each kind of activity. This list is different in composition of professionally important qualities, necessary degree of their intensity, character of correlation between them is determined by results of activity psychological analysis and description of professional and psychological parameters and demands.

The forming of PIQ subsystem is a quite complex psychological process. The main point of this process is a functional unification of single PIQ; therefore they start to work in the interaction mode. There are special inner preconditions to this, because basic mental functions are ontologically connected with each other. And this connection starts appearing positively during the mastering of professional activity. Thus some kind of functional adjustment of psychological functions to achieve the aims of activity is happening in the process of formation of psychological system.

The general structure of PIQ as main subjective determinants of labor activity is a quite difficult and internally differentiated. It includes number of basic PIQ categories, and its presence serve as main condition of professional activity's effective realization. At the same time the structure of PIQ defines structure of personality capabilities in point of peculiar activity.

There are number of Russian and foreign researches who concentrated on the problem of personality study, selection and evaluation its psychological peculiarities during activity, psychodiagnostics of individual psychological peculiarities (Gurevich, 1970; Klimov, 1998; Raygorodskiy, 2000, Sobchik, 2003; Eysenck, 1952; Eysenck, 1968; Cattell, 1990; Hall \& Lindsey, 1970; Anderson,1990; Atkinson, 1958; Bray \& Grant, 1966; Bray, 
Campbell, Grant, 1974; Eysenck, 1968; Fleishman, 1988; Harzberd, 1959; Maslow, 1954; Raven, 1997; Spencer, 1993; Wolf, 1995). Great value is attached to the study of personality development in the in the process of professional activity (Bodrov, 2001). The novelty of this research is consisted in use of longitudinal method in study intensity's degree and structure of personality's individual psychological peculiarities at the different stages of professional activity with the usage of profession's description approach and creation adequate to studying problem set of psychodiagnostic techniques. Used set of techniques allows to evaluate personality of workers in all variety of psychological and socio-psychological characteristics.

\section{Conclusion}

The problem of activity psychological study has very important, sometimes paramount meaning for identification of the most effective ways of decision for many practical problems. Study and analysis of activity implies its consideration like complex, multidimensional and multilayer, dynamically developing phenomenon. At the same time it is important to keep in mind that the practical task of the conduct of psychological analysis of the activity has some peculiarities (in the view of program, aims, methods, criteria, etc.). So for example such analysis provides substantiation of demands to content, development level, capabilities and professionally important qualities structure for solving problem of diagnostics and prediction of professional aptitude.

Human's capabilities, his professionally important qualities and functions are formed in labour, and their development possibilities are limited as peculiarities of this development process as well as the time limits. The causes of such condition are obstacles, limitations connected with: human's individual psychological peculiarities, insufficient working out of vocational training's theory and practice, enough dynamic characters of many activity's categories (that means their content, recourses, conditions change periodically) and at last, absence of taking into account individual peculiarities in the learning process and kind of activity.

First group of limiting factors is connected with possibilities' restriction and expressed individual differences of cognitive, psychomotor, emotional and volitional human characteristics which are necessary practically for any kinds of activity.

Second group of limiting factors reflects the high level of responsibility, complexity, danger of work tasks execution in set of professions and in this connection possibility of appearance of special mental states (as tense, stress, tiredness, mental demobilization, etc.), which breaks human psychosomatic status and capacity for work, cuts effectiveness and reliability of his activity.

Third group of limiting factors is connected with peculiarities of mental properties such as temperament, character, professional motivation which define steadiness, speed, mobility of human's mental activity, his communicative capabilities, incentive's and aspiration's orientation and intensity in activity; individual peculiarities of listed personality traits can't correspond with peculiar professional demands.

Fourth group of limiting factors is defined by character of labour activity and professional demands structure periodic variations, and also by possible professional re-orientation and retraining, which is as a rule accompanied by debalance of individual psychological capabilities and professional demands to the subject.

In that way, for a variety of causes the issue of evaluation psychological peculiarities of particular human, who wishes to dedicate himself to any profession, and also his professional success and the next practical activity prediction becomes so important.

Thus, the factors for consideration and selection when studying professional activity stages, which can cause professional destructions, allow to control and correlate both activity content and changes in structure of subject's psychological peculiarities.

\section{Recommendations}

Practical importance of this research consists in developed system of subject's psychological peculiarities diagnostic, which permits to predict necessary influences for achievement of higher level of professional successfulness on each stage of professional activity. Materials of this article can be used in practical activity of psychologists and HR-managers.

\section{Acknowledgments}

The work is performed according to the Russian Government Program of Competitive Growth of Kazan Federal University.

\section{References}

Anderson, J. A. (1990). Cognitive psychology and its implication (3rd ed.). N.Y: W.H. Freeman. 
Atkinson, F. (1958). Motives in fantasy, action and society. Princeton: Van Nostrand.

Bodrov, V. A. (2001). Psychology of professional integrity. In Textbook for instutions of higher education. M.: PER SE.

Bray, D. W., \& Campbell, R. J., \& Grant, D. L. (1974). Formative years in business: A long-term ATT study of managerial lives. N. Y.: Welye-lnterscience.

Bray, D. W., \& Grant, D. L. (1966). The assessment center in the measurement of potential for business management. Psychological Monographs, 80, 625. http://dx.doi.org/10.1037/h0093895

Cattell, R. B. (1990). The birth of the Society of Multivariate Experimental Psychology. Journal of the History of $\begin{array}{llll}\text { the } \quad \text { Behavioral } & \text { Sciences, } & \text { 48-57. }\end{array}$ http://dx.doi.org/10.1002/1520-6696(199001)26:1<48::AID-JHBS2300260105>3.0.CO;2-R

Eysenck, H. I. (1968). Biological base of personality. London.

Eysenck, H. J. (1952). The Scientific Study of Personality. London.

Flanagan, J. C., \& Krug, R. E. (1964). Testing in management selection stable of the art. Person Admin, 27, 33-39.

Fleishman, E. A. (1988). Some new frontiers in personnel selection research. Personnel Psychology, 41(4), 679-701. http://dx.doi.org/10.1111/j.1744-6570.1988.tb00647.x

Gurevich, K. M. (1970). Professional integrity and main features of the nervous system. M.: Science.

Hall, C., \& Lindsey S. G. (1970). Theories of Personality. New York: John Wiley and Sons.

Harzberd, F. (1959). Motivation to work. NY: Willey.

Ivanova. E. M. (1992) Psychological techniques of human study in the process of labour activity. In Textbookfor instutions of higher education for the departments of psychology. M.: MSU Publishing house.

Karpov, A. V. (1988). Psychological analysis of labour activity. Yaroslavl State University.

Klimov, E. A. (1988). Industrial psychology introduction. Textbook for instutions of higher education for the departments of psychology. M.: MSU Publishing house.

Markova, A. K. (1996). Psychology of professionalism. M.: “Znanie” MGF.

Maslow, A. (1954). Motivation and personality. NY.

Psychology of management and professional activity workshop. (2003). Spb.: Rech.

Raigorodsky, D. Y. (2000). Practical psychodiaognostic-Methods and tests. Samara: Publishing house "Bakhrar-M".

Raven, J. (1997). Competence in Modern Society: Its Identification, Development and Release. Unionville, NY: Royal Fireworks Press.

Shadrikov, V. D. (1994). Activity and abilities. M.: "Logos".

Sobchik, L. N. (2003) Psychology of individuality. In Theory and practice of psychodiagnostics. Spb.: "Rech".

Spencer, L. M., \& Spencer, S. M. (1993). Competence at work. New York :Wiley.

Sukcodolsky, G. V. (1988). Basic of psychological theory of labour. Publishing house of Leningrad University.

Wolf, A. (1995). Competence-Based Assessment. Buckingham: Open University Press.

\section{Copyrights}

Copyright for this article is retained by the author(s), with first publication rights granted to the journal. This is an open-access article distributed under the terms and conditions of the Creative Commons Attribution license (http://creativecommons.org/licenses/by/3.0/). 